\title{
THE ANTARES AMS CENTRE: A STATUS REPORT
}

\author{
CLAUDIO TUNIZ, ${ }^{1}$ DAVID FINK, ${ }^{1}$ MICHAEL HOTCHKIS, ${ }^{1}$ GERALDINE JACOBSEN, ${ }^{1}$ \\ EWAN LAWSON, ${ }^{1}$ ANDREW SMITH, ${ }^{1}$ QUAN HUA, ${ }^{1}$ PETER DREWER, ${ }^{1}$ PETER LEE, ${ }^{1}$ \\ VLADIMIR LEVCHENKO, ${ }^{2}$ ROGER BIRD,$^{1}$ JOHN BOLDEMAN,${ }^{1}$ MIKE BARBETTI, ${ }^{3}$ \\ GILLIAN TAYLOR ${ }^{3}$ and JOHN HEAD
}

\begin{abstract}
The ANTARES accelerator mass spectrometry facility at Lucas Heights Research Laboratory is operational and AMS measurements of ${ }^{14} \mathrm{C},{ }^{26} \mathrm{Al}$ and ${ }^{36} \mathrm{Cl}$ are being carried out routinely. Measurement of ${ }^{129} \mathrm{I}$ recently commenced and capabilities for other long-lived radioisotopes such as ${ }^{10} \mathrm{Be}$ are being established. The overall aim of the facility is to develop advanced programs in Quaternary science, global climate change, biomedicine and nuclear safeguards.
\end{abstract}

\section{INTRODUCTION}

A comprehensive accelerator mass spectrometry (AMS) facility for multi-isotope analysis based on high precision and high throughput has been under construction for the past four years at Lucas Heights Research Laboratories. To date, system development and progress have enabled $<1 \%$ precision ${ }^{14} \mathrm{C}$ measurements for near-modern samples. We review here the main features of the AMS center and its research directions, emphasizing recent achievements that characterize our level of precision and reproducibility. Highlights of the ANTARES (Australian National Tandem for Applied Research) AMS Centre were presented at the 6th AMS International Conference in Australia (Tuniz et al. 1994; Smith et al. 1994; Hotchkis et al. 1994; Fink et al. 1994).

\section{THE RESEARCH FACILITY}

The ANTARES AMS spectrometer is based on the FN tandem accelerator originally built by High Voltage Engineering for Rutgers University. Since arrival in Australia late in 1989, the accelerator has undergone a complete refurbishment and upgrade. Major items in this transformation are $100 \%$ SF6 insulating gas, a Dowlish accelerator tube, 59-sample computerized ion source, high-resolution $75-\mathrm{cm}$-radius injection magnet, an integrated system for fast sequential isotope injection and offaxis Faraday cups housed in enlarged magnet image chambers. Two dedicated beam lines using high-dispersion particle identification equipment enable versatility and efficiency in the detection of a variety of long-lived radioisotopes.

ANSTO received shipment of an 846B ion source from High Voltage Engineering Europa (HVEE) in July 1992. It comprised the spherical ionizer sputter source and associated power supplies, extraction electrode, 59 sample insertion mechanism and optical fiber telemetry to a control panel and PC at ground potential. Cathodes are rotated into position and an insertion arm with pneumatically operated jaws enters the cathode, pushing it through sprung fingers in the carousel and moving it forwards into the sample stage where it is deposited. The stage can be moved under computer control in the plane transverse to the cesium beam to avoid cratering effects and possible emittance changes. Despite 1000 successful sample changes prior to shipment, we experienced several failures of the sample-changing mechanism resulting in mechanical damage to the insertion arm assembly. We substantially modified the sample-changing mechanism to improve its reliability. We also made

\footnotetext{
${ }^{1}$ Australian Nuclear Science and Technology Organization, Private Mail Bag 1, Menai, NSW 2234 Australia

${ }^{2}$ Post Doctoral Fellow, National Greenhouse Advisory Committee grant (CSIRO, ANU, ANSTO) ${ }^{3}$ The NWG Macintosh Centre for Quaternary Dating, Madsen Building F09, University of Sydney, Sydney,
NSW 2006 Australia

${ }^{4}$ The Australian National University, Canberra, ACT 0200 Australia
} 
changes to guarantee accurate and reproducible alignment of the ion-optical components and replaced the extraction electrode with one of our own design.

Unexpected technical failures coupled with the necessity for design modifications considerably delayed installation of the new ion source. The 846B finally passed our acceptance test in late July 1994, and relocation of the source onto the injection beam line commenced in early August 1994. The acceptance test involved two days of continuous operation, changing randomly among 12 graphite targets spaced around the carousel. No problems with sample changing or performance were encountered and typical source outputs from commercial spectroscopic grade graphite powder were $100 \mu \mathrm{A}$, with some $70 \mu \mathrm{A}$ analyzed as ${ }^{12} \mathrm{C}$. On returning to a given cathode, the same source output was obtained within a few minutes. Beam profiles in the object plane of 4-5 mm FWHM were obtained and were on the optical axis within $1 \mathrm{~mm}$.

Fast sequential injection of isotopes is accomplished by modulating the pre-accelerated ion beam energy prior to mass selection with the injection magnet. The insulated magnet chamber is connected internally by mesh cylinders to specially designed gap lenses near the object and image planes, with external insulators joining the grounded beam line. High-voltage (HV) pulses are applied to this arrangement (capacitance $2.2 \mathrm{nF}$ ) by an HV operational amplifier (VAST Technology, Adelaide) to adjust the beam energy for an axial trajectory around the injection magnet through the equipotential region within the mesh cylinders and vacuum chamber. A versatile, custom-built waveform generator applies the HV levels by switching the input of the HV operational amplifier between up to 4 preset 12-bit DAC voltages using an analog multiplexer. The sequencer also generates a set of logic gates to coordinate integration of digitized stable isotope currents with radioisotope event recording by the detector, allowing for ion transit times and power supply response times. Both data types are transferred to the data acquisition interface (68030 CPU in VME) and sequentially added to the data buffer.

In April 1994, we performed an installation test of the reworked HV operation amplifier to improve the response time and spark immunity of the unit, following some earlier failures. The test showed that the rise and fall times of the voltage pulses were better than $300 \mu$ s to within $0.1 \%$ of the requested voltage over the full output range of -5 to $+5 \mathrm{kV}$ under load conditions.

Since then, isotope cycling has been in continuous operation for all our ${ }^{14} \mathrm{C}$ measurements. Once the required isotope cycle is loaded into the sequencer RAM, measurements proceed with mass 14 injected at zero bounce voltage and mass 13 injected during the $\mathrm{HV}$ portion of the cycle. The isotope cycling system can readily cope with the usual fluctuations and gradual increases seen in ion-source output. In practice, measurements of isotopic ratios to a precision of $0.5-1.0 \%$ can commence immediately after changing a sample in the single-sample ion source. Typically, a cycling frequency of $10 \mathrm{~Hz}$ with a $90-95 \%$ duty cycle is used; cycling at $20 \mathrm{~Hz}$ was tested with no apparent improvement in precision.

The sequencer also controls an electrostatic beam chopper, used to attenuate accurately intense stable isotope beams; we used this successfully during ${ }^{36} \mathrm{Cl}$ measurements earlier this year. The $846 \mathrm{~B}$ ion-source injection platform incorporates deflection plates prior to the pre-acceleration tube, with an improvement in chopping performance. The low-energy system will be completed later this year with the installation of an enlarged injector-image chamber housing three off-axis Faraday cups. We removed the beam buncher electrodes, originally at the accelerator entrance, to maximize the acceptance and accelerator transmission.

We use $\mathrm{SF}_{6}$ in the $\mathrm{FN}$ tank at a pressure of $c a .60 \mathrm{psi}$ and, at present, the maximum operating terminal voltage is $7.2 \mathrm{MV}$. With the addition of a new resistor column by end of 1994, we intend to 
progress to 9-10 MV. We installed a new NEC stabilizer, and GVM stability is typically $\pm 1.0 \mathrm{kV}$ at $7 \mathrm{MV}$. Carbon stripper foils $\left(2-5 \mu \mathrm{g} \mathrm{cm}^{-2}\right)$ are being used, but we consider them to be the major contributor to long-term drifts in our measurement of ${ }^{14} \mathrm{C}$ samples. A combined gas-foil stripper system is being manufactured and will be installed together with the new resistors. The entire vacuum system of the tandem is based on CT8 cryo pumps (1500 liter $\left.\mathrm{sec}^{-1}\right)$. Good vacuum in the accelerator tubes is essential and both the low- and high-energy ends of the tank are maintained at $10^{-5} \mathrm{~Pa}$. All gate valves, gauge heads and controllers are fully accessible and operative via the control computer.

The original HVE double-focusing high-energy analyzing magnet has been upgraded to a vacuum gap of $30 \mathrm{~mm}$ with an expanded chamber covering the full pole face area. An extended image chamber houses three off-axis cups that are adjustable with respect to their distance from the on-axis trajectory. These modifications have resulted in both full acceptance of off-axis ${ }^{12} \mathrm{C}$ beams into its cup (despite the high-energy quadrupole set at the rigidity for ${ }^{14} \mathrm{C}$ ) and $100 \%$ transmission of the selected, on-axis charge-state beam through the magnet. The ${ }^{13} \mathrm{C}$ off-axis cup has just been modified to provide a feedback signal for TV stabilization. It is split vertically, and current from each half will go to respective integrators for comparison to determine beam position. Accordingly, the TV will be adjusted under computer control to compensate for small changes in beam energy.

Beam lines at $35^{\circ}$ and $55^{\circ}$ to the multiported switcher magnet are used for AMS work. The former, dedicated for ${ }^{14} \mathrm{C}$ and ${ }^{26} \mathrm{Al}$, comprises a velocity filter and multi-anode ionization detector with $\mathrm{P} 10$ gas. A compact and retractable ${ }^{10} \mathrm{Be}$ detector is being constructed and will be inserted in the $35^{\circ}$ line before the ionization detector. In this way, measurement of either radioisotope will not interfere with the setup for the other.

The $55^{\circ}$ beam line was designed for measurement of other AMS radioisotopes requiring higher resolving power for background rejection. Extensive tests were made with ${ }^{36} \mathrm{Cl}$, and measurements of ${ }^{129} \mathrm{I}$ commenced on this beam line. It is equipped with a high-resolution $22^{\circ} \mathrm{ESA}$, time-of-flight (TOF) system and Bragg detector (all on loan from the National Institute of Nuclear Physics, Italy). At present, the TOF modules have been tested off-line and will be installed soon. With the Bragg detector, total energy, Bragg peak, energy loss and range can be extracted from the anode signal using a specially designed electronics module (Bassini et al. 1984).

Smith et al. (1994) presented details of the accelerator computer control setup. New, automatic scanning routines were recently developed for flat-topping ${ }^{14} \mathrm{C}$ and ${ }^{13} \mathrm{C}$ as a function of terminal voltage, injector field and "bounce" voltage. The scan profile is both tabulated and plotted in live-mode. Scanning procedures are performed at the beginning of each experiment, and when unacceptable, measurements are recorded on the ${ }^{14} \mathrm{C}$ standards. The multiparameter event-mode data (detector signals, current integrals, clock) is sorted fully on-line and stored on tapes. Both 1-D and 2-D spectra are available for inspection. We allow the sequencer to operate continuously and use the data acquisition computer to generate start-stop signals according to user-specified intervals. We consider a single ${ }^{14} \mathrm{C} /{ }^{13} \mathrm{C}$ determination to be the weighted mean of successive ratios obtained from a continuous 1000 -sec measurement period. Over this interval, ${ }^{13} \mathrm{C}$ and ${ }^{14} \mathrm{C}$ rates, integrals, dead-time, errors and isotopic ratios are printed to a running log-file about every $15-30 \mathrm{sec}$, depending on the ${ }^{14} \mathrm{C}$ event rate. On average conditions, for, say, the ANU sucrose, this would represent $1500-2500{ }^{14} \mathrm{C}$ counts per ratio. The log file can be ported into a program for calculation of fraction-modern and/or ${ }^{14} \mathrm{C}$ age.

We emphasize here that all our measurements were made using the single-sample 860 ion source. We are acutely aware of the limitations imposed on achievable precision and turn-around with such an ion source. On the other hand, we are surprised at the degree of success that can be recorded. This 
has been borne out particularly over the past three months in conjunction with the flawless operation of the isotope-cycling system and our attempts to reach $0.5 \%$ precision ${ }^{14} \mathrm{C}$ measurements for 12,500-yr-old individual tree-ring samples (see below).

For the past 12 months, we arranged, for both fast and slow cycling, that every 3rd or 4th measurement is on a standard, usually ANU sucrose. Unknowns are then normalized using the weighted mean or average derived from the two associated bracketing standards. The resultant precision associated with such a determination of the fraction modern of an unknown is then typically $1 \%$ for modern and near-modern samples. Figure $1 \mathrm{~A}-\mathrm{C}$ shows the results for a sequence of measurements comprising the determination on the Oxalic Acid I (HOxI) standard. Each data point represents a 10- to 15 -sec interval ( 125 bounces) and 71 ratios were generated. The mean value is $1120 \times 10^{-15}$, with a standard deviation of the mean $0.20 \%$ and a total Poisson uncertainty of $0.24 \%$. Hence, in the short term, i.e., during the $c a .15$ min required to make a single determination of the ${ }^{14} \mathrm{C} /{ }^{13} \mathrm{C}$ ratio, the stability and precision are dominated solely by counting statistics. To emphasize this point, Figure 2 shows a histogram of the standard deviation normalized to the associated Poisson uncertainty for 68 ${ }^{14} \mathrm{C} /{ }^{13} \mathrm{C}$ determinations, such as described above and shown in Figure $1 \mathrm{~A}-\mathrm{C}$. The histogram population refers only to the ANU sucrose and HOxI standards made over the last three months of operation, with each data point having a total Poisson uncertainty of $0.25-0.75 \%$. All except two standard measurements and those recorded during start-up and scanning were taken. The mean value for the ratio of external uncertainty to internal uncertainty is only slightly larger than unity, indicating that our precision is dominated by counting statistics.

Figure 3 demonstrates the long-term reproducibility during our recent measurements using fast cycling and the single-sample 860 source. Seven measurements of the HOxI standard are shown here taken over a 9-h period during which there was no retuning. The standard and Poisson uncertainties associated with each of these measurements are $c a .0 .2-0.4 \%$. The standard deviation of the complete distribution shown is $2.62 \%$, largely dependent on the Poisson statistics associated with an individual point ( 2000 counts, $2.24 \%$ uncertainty). The vertical lines represent periods during which measurements were made of unknowns. These periods were usually between $30 \mathrm{~min}$ and $1 \mathrm{~h}$. The good stability of our system allowed us to make measurements on eight consecutive 12,500 -yr-old tree rings with precisions of $c a .0 .5 \%$. The ${ }^{14} \mathrm{C} /{ }^{12} \mathrm{C}$ ratios associated with these measurements ranged from 220 to $240 \times 10^{-15}$ with standard and Poisson uncertainties of $0.4-0.7 \%$.

Clearly, stability over longer periods (i.e., days) is compromised by foil deterioration, imprecise resetting of the source extract and pre-acceleration voltages during cathode changes, slow drift in the terminal voltage and sputter cratering of the cathode. The new 60 -sample ion source, the gas stripper and terminal voltage stabilization with the split Faraday cup will be the key elements to extend sub-1\% reproducibility to longer measurement times.

Procedures for background correction require determination of the fraction of modern for blanks of known processed mass. We assume a fixed amount of modern contamination, and when accurately applied, the correction requires the same mass for blank and sample. However, once a process line is characterized, one can determine the fraction modern associated with a blank of any desired mass. We processed and measured a series of small mass blanks ranging from $65 \mu \mathrm{g}$ to $3 \mathrm{mg}$, resulting in consistent contamination level, independent of blank mass. Our complete process seems to be responsible for the addition of between 5 and $10 \mu \mathrm{g}$ of modern carbon contamination, of which graphitization is responsible for $c a .2 \mu \mathrm{g}$. A smaller volume combustion chamber and low-mass sample-graphitization lines are being constructed, which will further improve this figure. 

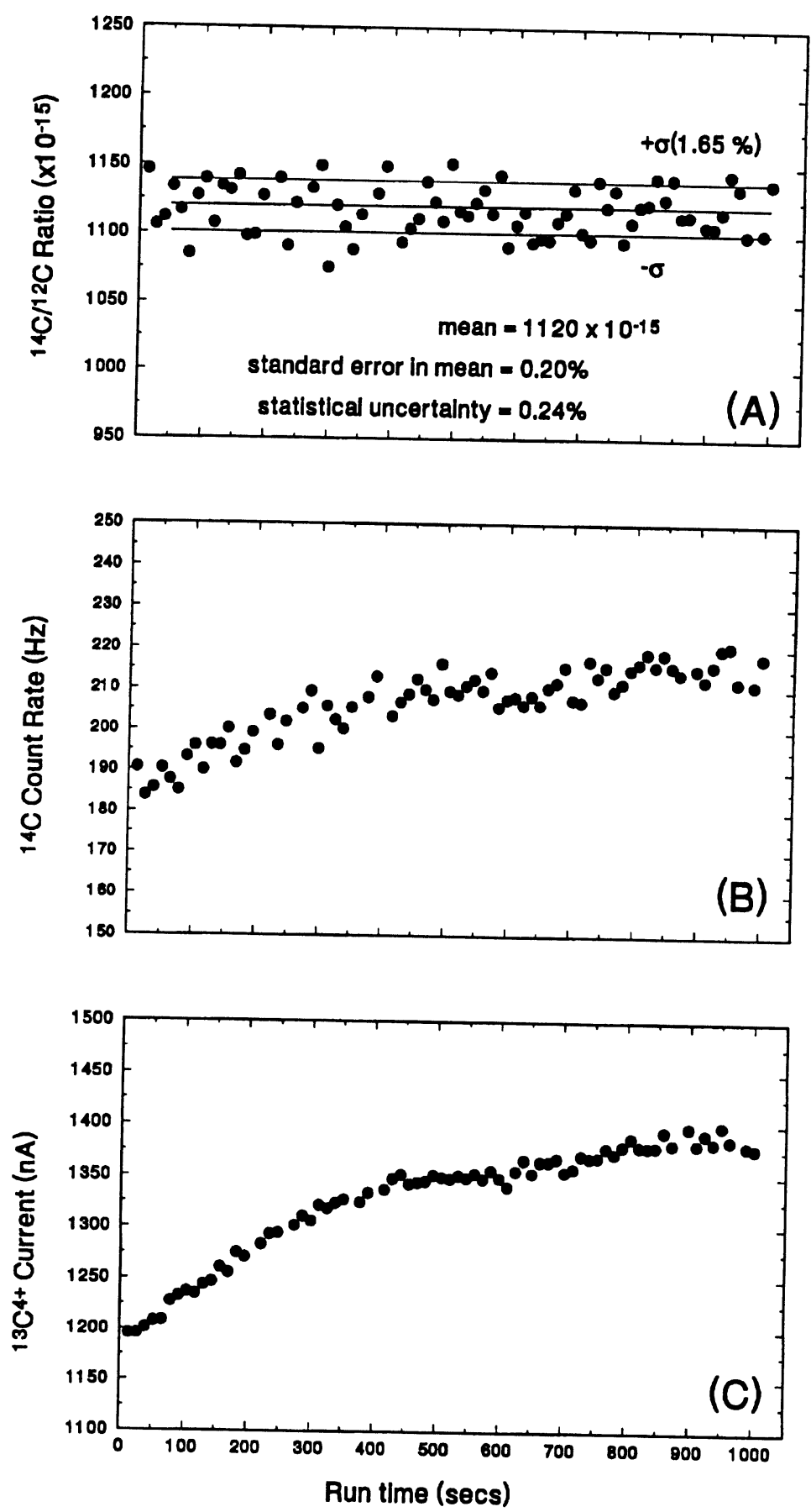

Fig. 1. Sequence of individual data for ${ }^{14} \mathrm{C} /{ }^{13} \mathrm{C}(\mathrm{A}),{ }^{14} \mathrm{C}$ (B) and ${ }^{13} \mathrm{C}(\mathrm{C})$ during a single determination of the HOxI standard. Each data point represents a 10-15-sec interval during which $2000{ }^{14} \mathrm{C}$ counts were collected. 


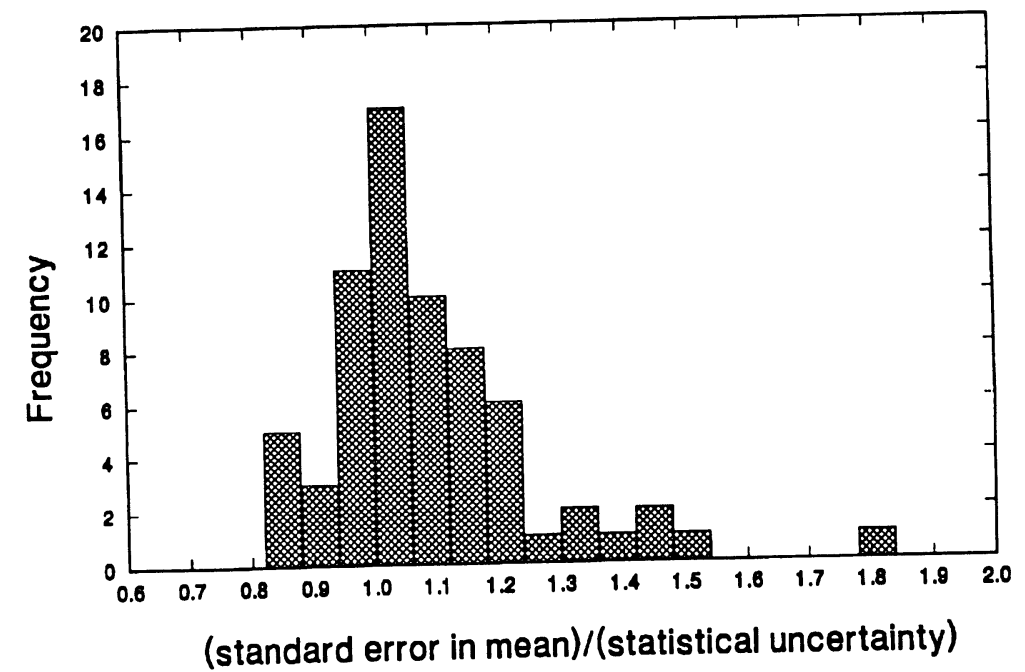

Fig. 2. Distribution of standard deviation of the mean normalized to the associated Poisson uncertainty for $68{ }^{14} \mathrm{C} /{ }^{13} \mathrm{C}$ determinations of ANU sucrose and HOxI standards made over the last three months of operation, each data point having a total Poisson uncertainty within $0.25-0.75 \%$

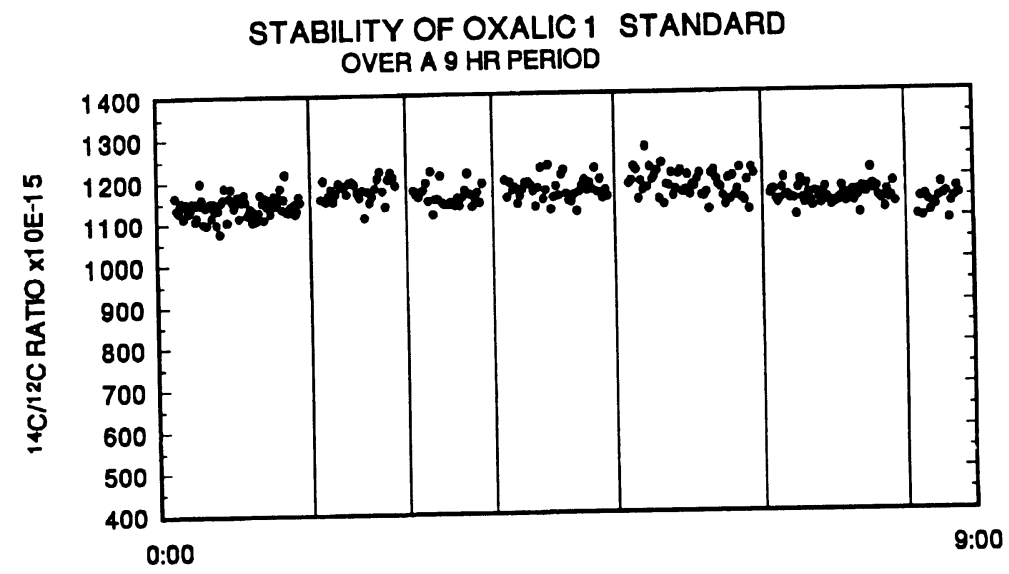

Fig. 3. Stability of the ANTARES AMS spectrometer over a continuous 9-h no-tune period. Each point represents a measurement involving ca. $2000{ }^{14} \mathrm{C}$ counts. The vertical lines represent periods when unknowns were measured.

We are now measuring ${ }^{26} \mathrm{Al}$ and ${ }^{36} \mathrm{Cl}$ routinely. Fink et al. (1994) successfully measured a set of biomedical ${ }^{26} \mathrm{Al}$ samples using the beamline at $35^{\circ}$. A sensitivity level of $5 \times 10^{-15}$, precision of $2 \%$, and $\mathrm{Al}^{-}$currents up to $500 \mathrm{nA}$ (from the 860 source) were achieved. During 1993, we measured ca. 30 scientific samples, 10 standards and blanks. More recently, we gained valuable experience in both the preparation of ${ }^{36} \mathrm{Cl}$ samples on-site at Lucas Heights and their measurement at ANTARES. ${ }^{36} \mathrm{Cl}$ AMS measurements were made at $6.8 \mathrm{MV}$ using the 7+ charge state with a slow cycling mode of operation. Transmission for the $7+$ ion beam to the detector cup is typically $13-17 \%$. We used the low-energy electrostatic chopper to attenuate the injected ${ }^{37} \mathrm{Cl}$ beam by $\mathrm{ca} .100$; repeat measurement 
of the ${ }^{35} \mathrm{Cl}^{7+} / \mathrm{Cl}^{7+}$ ratio at the image cup of the analyzer magnet indicated no correction for transmission fractionation. Effective injected ${ }^{37} \mathrm{Cl}^{-}$beams were of the order of $0.5-1 \mu \mathrm{A}$.

Both the ${ }^{14} \mathrm{C}$ line (ExB, ionization detector) and the $55^{\circ}$ line (Electrostatic Analyzer, Bragg detector) were used in ${ }^{36} \mathrm{Cl}$ measurements at $6.8 \mathrm{MV}$. The ESA readily removed all traces of the ${ }^{37} \mathrm{Cl}$ background that plagued our measurements using the ExB. Total energy resolution for both detectors were good (FWHM of $1.5 \%$ and $1.7 \%$, respectively). Comparison of the measured peak-to-peak separation (normalized to mean FWHM) for the ${ }^{36} \mathrm{~S}-{ }^{36} \mathrm{Cl}$ pair from each detector to calculations showed both acceptable and similar performances. The ESA was voltage-tested to $\pm 50 \mathrm{kV}$, allowing a maximum terminal voltage of $9 \mathrm{MV}$.

A set of Weeks Island halite samples were prepared at different locations to ascertain the limitations imposed by the proximity of the High Flux Australian Reactor (HIFAR) on achieving an acceptable ${ }^{36} \mathrm{Cl}$ sensitivity level of $1-2 \times 10^{-15}$. One sample was fully prepared on-site in our new clean-rooms and a second in Italy, at the Department of Earth Sciences, University of Turin. Both samples surprisingly resulted in ${ }^{36} \mathrm{Cl} / \mathrm{Cl}$ ratios of $20( \pm 7) \times 10^{-15}$. However, as the latter sample was pressed into the cathode on site, we suspected that reactor-based ${ }^{36} \mathrm{Cl}$ may still have entered the system. Empty (unloaded) $\mathrm{AgBr}$ cathodes were also measured and showed ${ }^{36} \mathrm{Cl}$ rates $5-10$ times lower than that from the Weeks Island halite blanks. A second series of elimination tests are in progress. We had hoped that, given the total separation of ${ }^{37} \mathrm{Cl}$ by the ESA, the remeasurement of the blanks might result in a lower value. We again obtained ${ }^{36} \mathrm{Cl} / \mathrm{Cl}$ ratios of $\sim 20 \times 10^{-15}$, adding to the burden of proof of on-site contamination. Reproducibility in the measurement of the $1200 \times 10^{-15}{ }^{36} \mathrm{Cl}$ standard is at present $\sim 5-7 \%$. Rates of ${ }^{36} \mathrm{~S}$ recorded in the Weeks Island and groundwater samples (also prepared at ANSTO) were typically $<75$ counts per second for corresponding ${ }^{37} \mathrm{Cl}^{7+}$ currents at the detector cup of 200-700 nA.

We made preliminary ${ }^{129} \mathrm{I}$ analyses on the ESA line at $6.4 \mathrm{MV}$, measuring two ${ }^{129} \mathrm{I} /{ }^{127} \mathrm{I}$ standards at $5 \times 10^{-9}$ and $5 \times 10^{-10}$ together with 2 commercial AgI blanks. Although our TOF system is not installed, we recorded a $5 \times 10^{-12}$ background level for these AgI blanks. With the standard sample, and using only the total energy signal of the Bragg detector, we were able to distinguish between mass 127 and 129 when the ESA was scanned across the different masses. For the AgI blank, we registered a 40 -fold increase in ${ }^{127}$ I count rate when the ESA was tuned for mass 127 . Further tests will continue after the installation of the TOF detector.

Two laboratories are devoted to the pretreatment of samples and preparation of AMS targets. The first laboratory is dedicated to sample curation and pretreatment; the second is a clean room for processing very small and low-level samples. In the last 12 months, we received $>800$ samples for ${ }^{14} \mathrm{C}$ analysis and ca. 150 samples for the analysis of other isotopes: ${ }^{26} \mathrm{Al},{ }^{10} \mathrm{Be},{ }^{36} \mathrm{Cl}$ and ${ }^{129} \mathrm{I}$. Physical and chemical pretreatment of the samples vary with sample type, so the laboratory is being set up to deal with all types of organic and inorganic samples. Treatments include cleaning by sonification, sorting, grinding and sieving, and chemical treatments such as the standard AAA treatment, acid digestion, solvent extraction and chromatography. A line for $\mathrm{CO}_{2}$ extraction from acidified water by purging with helium is also being installed, and preparation of targets for biomedical work involving ${ }^{14} \mathrm{C}$-enriched samples is under development.

Targets are prepared in the clean room, maintained under positive pressure and designed to prevent contamination from reactor-produced isotopes. For ${ }^{14} \mathrm{C}$ dating, oxidation, hydrolysis and graphitization are performed. Equipment is being upgraded to process large numbers of samples. The laboratory will comprise two oxidation and two hydrolysis lines (one for $>0.5 \mathrm{mg}$ samples and one for $<0.5 \mathrm{~g}$ samples) and an 8-sample-per-day graphitization system. Oxidation is achieved by heating 
the sample to $900^{\circ} \mathrm{C}$ in the presence of $\mathrm{CuO}$, and the gas is purified by passing over $\mathrm{Ag}$ and $\mathrm{Cu}$ wire at $600^{\circ} \mathrm{C}$. Graphitization is carried out by reducing $\mathrm{CO}_{2}$ with an iron catalyst $\left(600^{\circ} \mathrm{C}\right)$ in the presence of zinc $\left(400^{\circ} \mathrm{C}\right)$ and a small amount of hydrogen. Targets have also been prepared for ${ }^{26} \mathrm{Al},{ }^{10} \mathrm{Be}$ and ${ }^{36} \mathrm{Cl}$ analysis. This work involved such procedures as extracting aluminium from rat brains by precipitation as the 8-hydroxyquinoline complex and conversion to $\mathrm{Al}_{2} \mathrm{O}_{3}$ by ashing, extraction of chloride from waters by precipitation as $\mathrm{AgCl}$ and purification of the $\mathrm{AgCl}$, and extraction of beryllium from beryl. The capabilities of this laboratory will soon be expanded to include preparation of targets for ${ }^{129}$ I analysis from a variety of samples.

We developed a database with the ANSTO Computing Centre to track the incoming samples through the various procedures of submission, pretreatment, oxidation, graphitization, target loading and AMS analysis, so that, at any given time, the status of the sample can be ascertained.

\section{RESEARCH PROGRAM AND MEASUREMENTS}

The overall aim of the ANTARES AMS facility is to develop advanced programs in Quaternary science, global climate change, biomedicine and nuclear safeguards and other scientific and technological applications requiring ultrasensitive detection of long-lived radioisotopes. Figure 4 shows the distribution among different applications at the ANTARES AMS Centre for current projects (19941995). Since becoming operational about one year ago, the ANTARES AMS facility has been used to analyze some 500 samples from a variety of collaborative projects.
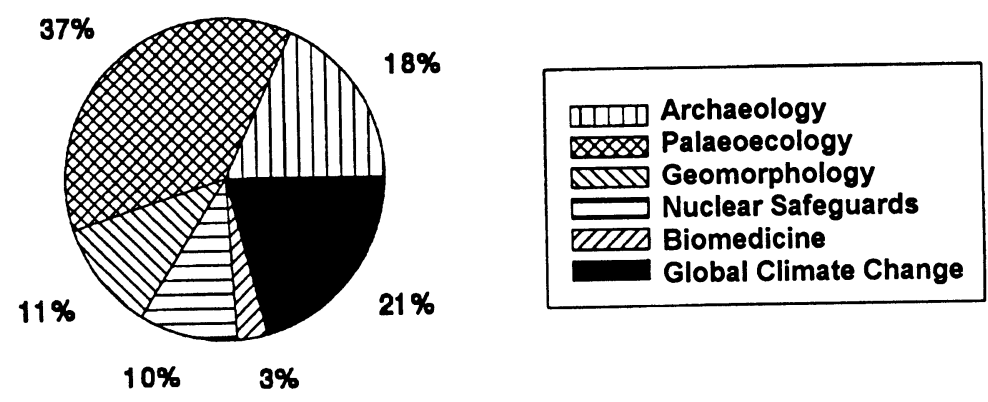

Fig. 4. Distribution among disciplines of the samples analyzed at the ANTARES AMS Centre for current projects (1994-1995)

The national research program in Quaternary science, funded by the Australian Research Council and the Australian Institute for Nuclear Science and Engineering involves collaboration with $>20$ Australian universities and AMS analysis of nearly 1000 samples from 80 projects covering a wide range of disciplines: archaeology, geomorphology, hydrology, palynology and paleoclimatology. The diversity of these projects is illustrated with some selected examples: dating of human/megafauna associations and environmental change in Australia (University of New South Wales), dating of prehistoric aboriginal rock pictures and burial sites (University of New England and of South Australia), ${ }^{14} \mathrm{C}$ and $\mathrm{U}$ analysis in corals to calibrate the ${ }^{14} \mathrm{C}$ time scale up to $40 \mathrm{ka} \mathrm{BP}$ (Australian National University), dating stick nest rat middens from inland Australia (University of New South Wales), the use of ${ }^{36} \mathrm{Cl}$ and ${ }^{129} \mathrm{I}$ for dating mineralization in the secondary zone of the Broken Hill Ore Body (University of Melbourne), glacial history of the Northern Prince Charles Mountains (Antarctica) using in-situ-produced ${ }^{10} \mathrm{Be}$ and ${ }^{26} \mathrm{Al}$ to model rock surface exposure history (Univer- 
sity of New England), long-term storage of components in the sub-arc mantle and its implications for the chemical evolution of the earth (University of Melbourne).

Many ancient conifer logs, exposed in the bed and banks of the Stanley River in western Tasmania, were sampled for dendrochronology and ${ }^{14} \mathrm{C}$ studies. Several major excavations were also made in floodplain sediments up to $100 \mathrm{~m}$ from the present river channel. Sections were collected from $>350$ well-preserved subfossil logs, ranging in age from $>38 \mathrm{ka}$ BP to the present, with good coverage for the periods $9-3.5 \mathrm{ka}$ BP and from $2.5 \mathrm{ka}$ BP to the present. Two species are represented in the collection: Huon pine (Lagarostrobos franklinii) and celery-top pine (Phyllocladus aspleniifolius), the former being more abundant. ${ }^{14} \mathrm{C}$ measurements were previously made on consecutive 10-ring samples from several logs, using liquid scintillation counting (LSC) for conventional ${ }^{14} \mathrm{C}$ dating (Barbetti et al. 1992). A cooperative project was established to measure the ${ }^{14} \mathrm{C}$ concentrations of 80 consecutive, single-ring samples from a celery-top pine log, dating from $c a .12,700 \mathrm{BP}$. These data will provide a short but precise annual record of atmospheric ${ }^{14} \mathrm{C}$ variations when plotted against ring numbers. The rings were separated by careful shaving, then milled and pretreated to isolate alphacellulose before combustion to $\mathrm{CO}_{2}$ and graphitization. Table 1 shows ${ }^{14} \mathrm{C}$ results from eight individual tree rings. The average ${ }^{14} \mathrm{C}$ age is $12,725 \pm 39 \mathrm{yr} \mathrm{BP}$, consistent with $12,645 \pm 54 \mathrm{yr}$ BP measured on the corresponding decadal sample with the Quantulus LS counter at the NWG Macintosh Centre

TABLE 1. AMS ${ }^{14} \mathrm{C}$ Dates from Annual Tree Rings of the Stanley River Celery-Top Pine Log, SRT-157

\begin{tabular}{cc}
\hline Tree-ring no. & $\begin{array}{c}\text { Age } \\
\text { (yr BP) }\end{array}$ \\
\hline 110 & $12,560 \pm 60$ \\
111 & $12,630 \pm 50$ \\
112 & $12,750 \pm 50$ \\
113 & $12,910 \pm 50$ \\
114 & $12,640 \pm 60$ \\
116 & $12,790 \pm 60$ \\
117 & $12,750 \pm 70$ \\
118 & $12,750 \pm 50$ \\
\hline
\end{tabular}

Tooth enamel separated from ancient fossil animal teeth (previously dated using electron spin resonance (ESR) dating) was examined by selective heating at $600^{\circ}, 750^{\circ}$ and $950^{\circ} \mathrm{C} . \mathrm{CO}_{2}$ generated from decomposition of the samples at the respective temperatures was collected for $\delta^{13} \mathrm{C}$ determination and ${ }^{14} \mathrm{C}$ dating. Results indicate that the organic component exchanged with younger organic materials, and large amounts of carbonate replaced phosphate in the hydroxyapatite of the enamel. Continuous carbonate exchange is also postulated. No concrete conclusions can be reached at this stage, but the results were unexpected and further work is needed to adequately explain observations and measurements.

The Venafro chessmen, Arabic-style bone chess pieces, discovered in a Roman tomb in 1932 in Venafro, a small Roman town in Southern Italy, are extremely interesting archaeological finds. Dating the animal bones from which these artifacts were made at both the ANTARES AMS Centre and the AMS facility of Naples resulted in dates $87.1 \pm 0.9$ and $88.0 \pm 1.8 \mathrm{pMC}$, respectively. The aver- 
age of the two results corresponds to a ${ }^{14} \mathrm{C}$ age of $1090 \pm 70 \mathrm{yr}$ BP and cal $\mathrm{AD} 885-1017$ (1 $\sigma$ ) (Terrasi et al. 1994), compatible with the hypothesis that this game was introduced to Central Italy during the Saracen invasions of the 9th century AD.

The Australian National Greenhouse Advisory Committee funded two ${ }^{14} \mathrm{C}$ AMS projects to study the effect of the ocean carbon cycle on the atmospheric $\mathrm{CO}_{2}$ budget and the record of past climate changes archived in Antarctic ice cores. The aim of the first project (in collaboration with CSIRO, Oceanographic Division, Antarctic CRC and Flinders University) is to determine the contribution of the Southern Ocean toward the ventilation of the world oceans, and to quantify its performance as a sink for anthropogenically produced greenhouse gases. It is still unclear what accuracy global ocean models have in representing features of the Southern Ocean circulation. Transient tracers (such as ${ }^{14} \mathrm{C}$ ) can be used to test these models. Collection of tracer data is being undertaken through the World Ocean Circulation Experiment. Our program will provide data in the Australian region and, in particular, parts of the Southern Ocean. Many of the samples have already been collected and interlaboratory calibration with the National Ocean Sciences AMS Facility at Woods Hole (USA) is planned to check the accuracy of AMS analysis.

The aims of the second project (in collaboration with CSIRO Atmospheric Division, Antarctic Cooperative Research Center and Australian National University) are: 1) to test models for predicting the ${ }^{14} \mathrm{C}$ age span in an annual layer of ice; and 2) to detect natural ${ }^{14} \mathrm{C}$ variations related to climate forcing and other natural causes in the 1-km, high-resolution ice core from Law Dome (Antarctica), extending back to $40 \mathrm{ka}$ BP. The interval is evaluated by measuring, in the Law Dome ice core, the rapid increase in atmospheric ${ }^{14} \mathrm{C}$ due to nuclear weapons testing in the late 1950 s and early 1960s. These ice cores are characterized by an unparalleled time resolution and are the best source of ancient air to constrain projections of future levels of greenhouse gases. The main effort at the moment is the improvement in techniques for ${ }^{14} \mathrm{C}$ preparation and analysis of $10-50-\mu \mathrm{g}$ samples.

A limited AMS program in biomedicine has been activated at the ANTARES facility. In conjunction with the Sydney Water Board and the Australian Institute for Biomedical Research, we demonstrated the presence of ${ }^{26} \mathrm{Al}$, ingested from drinking water, in brain tissues of aged and young rats (Fink et al. 1994). A second biomedical experiment involving ${ }^{14} \mathrm{C}$ tracer studies of ethanol carcinogenicity is being developed with the Department of Biochemistry, University of Queensland.

We are developing analyses of ${ }^{129} \mathrm{I}$ in safeguards monitoring, which will also include $\mathrm{U}$ and $\mathrm{Pu}$ analyses. A third all-electrostatic beam line equipped with a high-resolution electrostatic analyzer and a TOF detector is being designed for the $0^{\circ}$ port of the analyzing magnet. We analyzed ${ }^{36} \mathrm{Cl}$ and ${ }^{14} \mathrm{C}$ in groundwaters near uranium mines to study the water-rock interaction (with the Universities of Paris-Sud and Turin).

An exciting discovery in recent years in nuclear physics was so-called exotic radioactivity: the spontaneous emission of heavy ions such as ${ }^{14} \mathrm{C},{ }^{20} \mathrm{Ne}$ and ${ }^{24} \mathrm{Ne}$ from nuclei in the trans-lead region. This decay mode was tested by groups at Berkeley, Dubna, Orsay and Milan mostly with nuclear track detector techniques. With the Universities of Milan and Turin, we started an experiment to measure ${ }^{14} \mathrm{C}$ abundances in $\mathrm{U}$ and Th ores by AMS. ${ }^{14} \mathrm{C}$ clusters are emitted by ${ }^{223} \mathrm{Ra}$ and ${ }^{224} \mathrm{Ra}$ present in the natural decay series of ${ }^{235} \mathrm{U}$ and ${ }^{232} \mathrm{Th}$, respectively. The corresponding theoretical branching ratios relative to $\alpha$ decay are $10^{-9.2}$ and $10^{-10.3}$, respectively. One can estimate that ${ }^{14} \mathrm{C}$ will build up to an equilibrium concentration of $1.4 \times 10^{5}$ atoms per gram $U$ and $10 \times 10^{4}$ atoms per gram of Th in natural minerals. A few tens of grams of U or Th will suffice for AMS analysis. Similar measurements were made at the NSF-Arizona AMS Facility (Jull, Barker and Donahue 1988). Results were not conclusive due to the competing production of ${ }^{14} \mathrm{C}$ from the ${ }^{11} \mathrm{~B}(\alpha, \mathrm{p}){ }^{14} \mathrm{C}$ reaction. For the present 
experiment, $c a .15$ mineral samples from Australia and Europe were collected. The first phase of the experiment involved the development of the technique to extract the $\mathrm{CO}_{2}$ fraction of interest by successive heating to $1500^{\circ} \mathrm{C}$.

\section{CONCLUSION}

The performance of the ANTARES AMS spectrometer improves steadily in terms of precision and control of background. Isotopic ratios of ${ }^{14} \mathrm{C}$ samples can be measured with an uncertainty of $<1 \%$. Further improvement in precision will derive from the installation of the gas stripper and the use of the 59-sample source. Initial ${ }^{36} \mathrm{Cl}$ and ${ }^{129} \mathrm{I}$ experiments on the beam line dedicated to high-mass radioisotopes show good performance of the electrostatic analyzer and of the Bragg chamber. The research program based on the ANTARES AMS facility is part of a multidisciplinary effort aimed at studying an array of problems concerning the international community such as global climate change, soil erosion, environmental pollution, nuclear waste management and nuclear safeguards.

\section{ACKNOWLEDGMENTS}

The research program at the ANTARES AMS Centre is partially supported by grants from the Australian Institute of Nuclear Science and Engineering, the Australian Research Council and the National Greenhouse Advisory Committee. Our recent work benefitted from collaboration with many people, including E. Sacchi, R. Bonetti, G. M. Zuppi, J.-L. Michelot and F. Terrasi. The success of our work relies on the skills of the accelerator group at ANSTO, led by John Fallon.

\section{REFERENCES}

Bassini, R., Iori, I., Moroni, A., and Taiocchi, G. 1984 A compact electronic apparatus for the Bragg-Curve analysis in axial ionization chambers. Report INFN/ TC 84-23.

Barbetti, M., Bird, T., Dolezal, G., Taylor, G., Francey, R., Cook, E. and Peterson, M. 1992 Radiocarbon variations from Tasmanian conifers: First results from late Pleistocene and Holocene logs. In Long, A. and Kra, R. S., eds., Proceedings of the 14 th International ${ }^{14} \mathrm{C}$ Conference. Radiocarbon 34(3): 806-817.

Fink, D., Walton, J., Hotchkis, M. A. C., Jacobsen, G. E., Lawson, E. M., Smith, A. M., Tuniz, C. and Wilcox, D. 1994 First ${ }^{26} \mathrm{Al}$ analyses at the ANTARES AMS Centre: Uptake via oral ingestion of ${ }^{26} \mathrm{Al}$ in aged rats. In Fifield, L. K, Fink, D., Sie, S. H. and Tuniz, C., eds., Proceedings of the 6th International Conference on Accelerator Mass Spectrometry. Nuclear Instruments and Methods in Physics Research B92: 473-477.

Hotchkis, M. A. C., Fink, D., Jacobsen, G. E., Lawson, E. M., Shying, M., Smith, A. M., Tuniz, C., Barbetti, M., Grave, P., Hua Minh Quan and Head, J. $1994{ }^{14} \mathrm{C}$ analyses at the ANTARES AMS Centre: Dating the log coffins of northwest Thailand. In Fifield, L. K, Fink, D., Sie, S. H. and Tuniz, C., eds., Proceedings of the 6th International Conference on Accelerator Mass Spectrometry. Nuclear Instruments and Methods in Physics Research B92: 27-30.
Jull, A. J. T., Barker, D. L. and Donahue, D. J. 1987 On the ${ }^{14} \mathrm{C}$ content in radioactive ores. Chemical Geology (Isotope Geoscience Section) 66: 35-40.

Smith, A. M., Fink, D., Hotchkis, M. A. C., Jacobsen, G. E., Lawson, E. M., Shying, M., Tuniz, C., Watt, G. C., Fallon, J. and Ellis, P. J. 1994 Equipment and methodology for high precision, high throughput ${ }^{14} \mathrm{C}$ AMS analyses at ANTARES. In Fifield, L. K, Fink, D., Sie, S. H. and Tuniz, C., eds., Proceedings of the 6th International Conference on Accelerator Mass Spectrometry. Nuclear Instruments and Methods in Physics Research B92: 122-128.

Terrasi, F., Campajola, L., Petrazzuolo, F., Brondi, A., Cipriano, M., D’Onofrio, A., Quian Zhi Hua, Roca, V., Romano, M., Romoli, M., Tuniz, C. and Lawson, E. 1994 Datazione radiocarbonica degli scacchi di Venafro con il metodo della spettrometria di massa con acceleratore. L' Italia Scacchistica 1064: 48-60.

Tuniz, C., Fink, D., Hotchkis, M. A. C., Jacobsen, G. E., Lawson, E. M., Smith, A. M., Bird, J. R. and Boldeman, J. W. 1994 The ANTARES AMS Centre at Lucas Heights Research Laboratories. In Fifield, L. K, Fink, D., Sie, S. H. and Tuniz, C., eds., Proceedings of the 6th International Conference on Accelerator Mass Spectrometry. Nuclear Instruments and Methods in Physics Research B92: 22-26. 